This document is published in:

P. Alvaredo, D. Mari, E. Gordo, High temperature transformations in a steel-TiCN cermet, International Journal of Refractory Metals and Materials, available online 27 Feb. 2013,

DOI: http://dx.doi.org/10.1016/j.ijrmhm.2013.02.012

(C) 2013 Elsevier 


\begin{abstract}
Elsevier Editorial System(tm) for
International Journal of Refractory Metals and Hard Materials

Manuscript Draft
\end{abstract}

Manuscript Number:

Title: High temperature transformations in a steel-TiCN cermet.

Article Type: Research Paper

Keywords: Cermet, Internal friction, Phase transformation, Differential thermal analysis

Corresponding Author: Mrs PAULA ALVAREDO,

Corresponding Author's Institution: UNIVERSITY CARLOS III MADRID

First Author: PAULA ALVAREDO, PhD

Order of Authors: PAULA ALVAREDO, PhD; DANIELE MARI, PhD; ELENA GORDO

Abstract: The influence of the carbon content on the microstructure, phase transformation and hardness of an iron-based cermet is studied. The cermet is constituted by a high-alloyed steel as matrix, and TiCN particles (50 vol. \%) as reinforcement. The material is produced by conventional powder metallurgy techniques, that is, uniaxial pressing and sintering, and the carbon content is varied from 0 wt $\%$ to 1 wt $\%$ The aim of the research is the understanding of the transformations undergone by the material with increasing $\mathrm{C}$ amounts when temperature is increased. For this purpose, the cermet is studied by Mechanical Spectroscopy (MS) and Differential Thermal Analysis (DTA) and characterized by XRD, SEM and hardness measurements. The equilibrium phase diagram calculated by Thermocalc software contributes to explain the differences found on phase transformations with respect to the $\mathrm{C}$ content of the cermet. 


\title{
High temperature transformations in a steel-TiCN cermet.
}

\author{
P. Alvaredo ${ }^{a}$, D. Marib, E. Gordo ${ }^{a}$ \\ a University Carlos III Madrid. Avenida de la Universidad, 3028911 Leganés. Madrid \\ ${ }^{b}$ Ecole Polytechnique Fédérale de Lausanne. CH-1015 Lausanne, Switzerland \\ Corresponding author. Tel. +34916248862; Fax.: +34916249430. Email: elena.gordo@uc3m.es
}

\begin{abstract}
The influence of the carbon content on the microstructure, phase transformation and hardness of an iron-based cermet is studied. The cermet is constituted by a high-alloyed steel as matrix, and TiCN particles (50 vol. \%) as reinforcement. The material is produced by conventional powder metallurgy techniques, that is, uniaxial pressing and sintering, and the carbon content is varied from 0 wt $\%$ to 1 wt \%. The aim of the research is the understanding of the transformations undergone by the material with increasing $\mathrm{C}$ amounts when temperature is increased. For this purpose, the cermet is studied by Mechanical Spectroscopy (MS) and Differential Thermal Analysis (DTA) and characterized by XRD, SEM and hardness measurements. The equilibrium phase diagram calculated by Thermocalc software contributes to explain the differences found on phase transformations with respect to the $\mathrm{C}$ content of the cermet.
\end{abstract}

\section{Keywords}

Cermet, Internal friction, Phase transformation, Differential thermal analysis

\section{Introduction}

Iron-matrix cermets are an interesting and promising group of metal matrix composites which could compete in cutting and forming applications with some conventional cermets and cemented carbides (containing $\mathrm{Ni}$ and $\mathrm{Co}$ as matrix elements). The interest of these materials are related to environmental and health issues, as $\mathrm{Co}$ and $\mathrm{Ni}$ are scarce, expensive and strategic materials; in particular, WC-Co has been included in the latest report of the US Department of Health \& Human Services '12th Report on Carcinogens', published on June 11, 2011, as one of 240 substances that may increase risk for cancer. Similarly, the International Agency for Research on Cancer (IARC) has listed nickel compounds within group 1 (there is sufficient evidence for carcinogenicity in humans) and $\mathrm{Ni}$ metallic and alloys as 2B (possibly carcinogenic to humans). In front of these metals, Fe is a nontoxic, abundant, and lower cost metal that can also be hardened by heat treatment [1] thus reducing the need for amounts of ceramic content as high as conventional cermets. There are however some disadvantages, mainly related to the processing, due to the lower wettability during liquid phase sintering between iron and TiCN particles than Ni and Co matrixes [2], and to the risk of producing reaction products that lead to embrittlement. The addition of some elements or compounds, such as $\mathrm{Mo}, \mathrm{Mo}_{2} \mathrm{C}$ or WC [3-6], as well as $\mathrm{Cr}[3,7]$ have been reported to improve the sintering performance of cermets. The addition of those alloying elements to the $\mathrm{Fe}$ matrix also increases hardness and hardenability, as well as the volume fraction of carbides formed during sintering that increase the total amount of the ceramic phase. Therefore, a commercial alloy containing Mo, W, $\mathrm{Cr}$ and $\mathrm{V}$ was selected as matrix for the development of the Fe-based cermet present in this work.

Besides the alloying elements, the $\mathrm{C}$ content has also a great influence on the final properties of the cermets. Many research works have highlighted the influence of the carbon content on the properties 
of $\mathrm{Ni} / \mathrm{Co}-\mathrm{TiCN}$ cermets [7-10]. However, there are no systematic studies on the influence of the C content on Fe matrix composites, a former paper by the authors of this work illustrated the variation of mechanical properties as well as of the microstructural changes in several systems formed by Fe and TiCN [11]. The complex microstructure shown in these cermets and the complex relations among the constituents make it difficult to identify the parameters affecting the final properties. Moreover, these Fe-based cermets can be heat treated to improve the hardness and strength, and it is necessary to understand their effects. Mechanical Spectroscopy (MS) has been selected as a technique to study these phenomena, as it has demonstrated to be a useful tool to investigate the mechanical properties and their relation with microstructure of complex materials as cermets [12,13]. Other techniques such as Thermoelectric Power (TEP), Differential Thermal Analysis (DTA) and Thermomagnetometry are used in this study for a better understanding of the phenomena involved. The theoretical phase diagram of the system, calculated by Thermocalc software, helps to explain some of the experimental results.

Mechanical Spectroscopy is a technique that measures the damping capacity of a material [14] that derives from energy dissipation. If a periodic stress is applied to the sample $\left(\sigma(t)=\sigma_{0} \sin (i \omega t)\right.$ ), the strain $\left(\varepsilon(t)=\varepsilon_{0} \sin (i[\omega t-\phi])\right)$ lags behing stress by a phase lag $\phi$. The energy dissipation occurs because of dislocation motion, grain boundary migration and grain-boundary sliding.

The thermoelectric power (TEP), also known as Seebeck coefficient (S) or simply thermopower, is a measure of the Seebeck effect. This effect consists in the appearance of an open circuit voltage, $\Delta \mathrm{V}$, when a temperature difference, $\Delta \mathrm{T}$, is applied along a sample. The thermoelectric power is then defined by

$$
S=\lim _{\Delta T \rightarrow 0}\left(\frac{\Delta V}{\Delta T}\right)
$$

The combination of both techniques has been used before by Mari et. al, to analyze the microstructural changes in steels [15-17]; in particular, room temperature thermoelectric power has been previously found to vary inversely to the concentration of interstitial $C$ in ferrite [18] and martensite [19]. In this work, the same techniques are used to study the influence of the $C$ content on the behavior of an iron-based cermet reinforced with TiCN particles.

\section{Experimental procedure}

The investigated composite materials consist of a Fe alloy matrix and 50 vol\% of $\mathrm{TiC}_{0.5} \mathrm{~N}_{0.5}$ particles as reinforcement. The composition of the Fe alloy is 6.2 wt. \% W, 4.8 wt. \% Mo, 4.1 wt. \% Cr, 1.8 wt. \% V and 0.85 wt. \% C, which corresponds to the high-speed steel grade M2, used as prealloyed powder, as it contains all the elements desired for the matrix. To study the effect of the carbon content, different amounts of graphite were added to the matrix leading to materials with composition [M2 $+\mathrm{X}$ wt. \% C] + TiCN 50 vol. \%, where $X$ is $0,0.5$ and 1 . To facilitate the reading comprehension the samples are denoted as S0, S05 and S1, respectively. The density and particle size of the starting powders are given in Table 1

Table 1. Characteristics of raw materials.

The powders were blended during 4 hours in a Turbula ${ }^{\circledR}$ multidirectional mixer, and then processed by the conventional powder metallurgy route (CPS): uniaxial pressing at $700 \mathrm{MPa}$ into rectangular bars $(31.6 \times 12.9 \times 4 \mathrm{~mm})$ and sintering in vacuum $\left(10^{-4} \mathrm{mbar}\right)$ at $1400^{\circ} \mathrm{C}$ during 60 minutes. 
The density of the processed samples was measured by He pycnometry, while the hardness was measured in the Vickers scale with $30 \mathrm{~kg}$ load (HV30). X-ray diffraction (XRD) and scanning electron microscopy (SEM) were used for crystallographic and microstructural analysis, respectively.

A thermodynamic simulation of the equilibrium phase diagram of the cermet was performed using ThermoCalc software [20]. Calculations are based on the Gibbs free energy minimization code and mass conversion rule, in combination with the TCFE5 database (Scientific Group Thermodata Europe).

The thermal behaviour of the sintered samples was investigated by Differential Thermal Analysis (DTA) in a SETARAM equipment (SETSYS Evolution 16/18). The analyses were performed in an $\mathrm{Al}_{2} \mathrm{O}_{3}$ crucible under $\operatorname{Ar}(99.999 \%)$ atmosphere up to $1500{ }^{\circ} \mathrm{C}$, with heating and cooling rates of $10^{\circ} \mathrm{C} / \mathrm{min}$.

The Curie temperature was determined by thermomagnetometry measurements [21] performed in a Perkin-Elmer TGA7 Thermogravimetric Analyser equipped with a small permanent magnet. The measurements were performed at temperature up to $900{ }^{\circ} \mathrm{C}$ with a heating rate of $10^{\circ} \mathrm{C} / \mathrm{min}$. The magnet was kept during all the measurements in the same position, as much as possible, to ensure that the magnetic field gradient affecting the samples was the same.

Mechanical Spectroscopy (MS) measurements were performed by means of a forced inverted torsion pendulum working at a constant frequency of $1 \mathrm{~Hz}$. Sintered samples $(30 \times 3 \times 0.5 \mathrm{~mm})$ were submitted to three heating cycles increasing the upper temperatures (1100K, $1250 \mathrm{~K}$ and $1350 \mathrm{~K})$.

TEP measurements were carried out at room temperature placing the sintered sample $(30 \times 3 \times 0.5$ $\mathrm{mm}$ ) between two copper blocks at $10^{\circ} \mathrm{C}$ and $30^{\circ} \mathrm{C}$, respectively.

\section{Results}

\section{Microstructural study}

Representative microstructures of sintered samples with different $\mathrm{C}$ additions ( 0 wt. \%, 0.5 wt. \% and 1.0 wt. \%) are shown in Figure 1. Three main phases can be observed in all the samples: a grey metallic matrix, black TiCN particles and a brighter phase corresponding to the carbides of the alloying elements from the high speed steel matrix. This brighter phase is mainly located at the interface between the metallic matrix and the ceramic TiCN particles and it is formed by a dissolutionprecipitation mechanism of the steel carbides during the sintering process, taking into account that densification occurs by liquid phase sintering. At the beginning of the sintering cycle, during heating, the alloying elements dissolved in the high-speed steel powder particles precipitate in the form of carbides; in a later stage, as the temperatures involved in the sintering process of the composite are above the usual sintering temperatures of the high-speed steel, the carbides are re-dissolved into the metallic matrix and, upon cooling down, they are reprecipitated between the TiCN particles and the matrix, using the TiCN particles as nucleation points.

Figure 1: Microstructures of sintered samples S0, S05 and S1 ([M2 + x]/TiCN $(x=0,0.5,1.0$ wt. \% C))

Some differences can be found in the microstructure of the samples with no $\mathrm{C}$ addition with respect to those containing 0.5 and $1 \mathrm{wt}$. \% C: the former is less homogeneous containing rounded metal matrix areas and showing the existence of bright carbides, appearing not only around the TiCN particles but also precipitated in the metal matrix. A more detailed explanation of the sintering mechanisms leading to these different microstructures can be found in [11]. 
The microstructural differences are also related to the sintered density and hardness, as shown in Table 2.

Table 2. Hardness and relative density of sintered samples S0, S05 and S1

Note that the density is expressed as relative density, that is, values obtained by pycnometry with respect to the theoretical density of each composition. This is a common way to express density in PM products, since it gives an indication of the residual porosity. The relative density of the samples containing 0.5 and $1 \mathrm{wt}$ \% $\mathrm{C}$ is higher than $100 \%$ meaning that they are fully dense. Relative density values exceeding $100 \%$ are due to the reactions occurring during sintering, provoking changes in phase composition and the precipitation of a large number of carbides that change the initial theoretical density value $\left(6.56 \mathrm{~g} / \mathrm{cm}^{3}\right.$ for $0 \% \mathrm{C}$ added).

By observing the hardness of samples with $\mathrm{C}$ addition it is worth noticing that hardness is almost twice in comparison with the sample with no $\mathrm{C}$ added. This effect could be related to different causes. First, the nature of the carbides may be different in samples with $C$ addition since they are formed by a dissolution-reprecipitation mechanism. Instead, in samples with no $\mathrm{C}$ added the carbides are primary carbides formed by precipitation from the powder particles. The carbides in the $\mathrm{C}$ added samples are located surrounding the TiCN particles while in S0 they precipitate inside the former steel particles. The size of the steel areas that are free of TiCN particles it is clearly different on figure 1, and also phase transformations in the steel matrix.

$\mathrm{XRD}$ analysis of the samples [M2+X \%wt. C]+TiCN are shown in Figure 2. Peaks corresponding with TiCN reinforcement and steel matrix can be observed in the three difractograms, as well as peaks due to the carbides of the alloying elements of the high speed steel matrix. The analysis of samples with $\mathrm{C}$ addition (S05 and S1) show peaks corresponding with austenite while this phase is not found in the analysis of the sample with no $\mathrm{C}$ addition (S0). Both, the presence of retained austenite and the higher hardness found in samples with $\mathrm{C}$ added, could indicate the presence of martensite in the steel matrix.

Figure 2: XRD analysis of S0, S05 and S1 sintered samples (bottom to top respectively).

Mechanical Spectroscopy (MS) and Thermoelectrical Power (TEP)

Mechanical loss spectra (as a function of temperature) (up to $1100 \mathrm{~K}\left(827^{\circ} \mathrm{C}\right)$ ) of samples S0, S05 and $\mathrm{S} 1$ are represented in Figure 3 for the first heating cycle. The highest damping of the mechanical loss is found on the spectrum of sample with $0.5 \mathrm{wt} . \% \mathrm{C}$ while the lowest damping of the mechanical loss is found on the spectrum of the sample with no $C$ addition. As it has been observed in XRD analysis there is a microstructural change in the steel matrix of the cermet by increasing the $C$ content, the presence of different phases on the steel matrix of the samples with $C$ added could provoke changes in the magnetic properties of the sintered samples, which is reflected in the internal friction during the magnetic transformation.

Figure 3: Comparison of first heating (up to $1100 \mathrm{~K}\left(827^{\circ} \mathrm{C}\right)$ ) spectra of sintered samples S0, S05 and S1.

Thermopower measurements (TEP) are found to be very sensitive to the composition and to the microstructure of a material, as has been mentioned previously. Room temperature thermoelectric power has been previously found to vary inversely with the concentration of interstitial C [16, 17, 19]. The Seebeck coefficients values found in TEP measurements of the sintered samples, S0, S05 and $\mathrm{S} 1$ are $-0.08 ;-2,8$ and $-1,7 \mu \mathrm{V} / \mathrm{K}$, respectively. Figure 4 shows the comparison of the Seebeck coefficients with the internal friction measured at $1100 \mathrm{~K}$ upon heating of the first heating in MS measurements and with the hardness of the samples; the combination of the results of both 
techniques indicates a higher amount of $C$ in solid solution in the steel matrix of the sample S05 and $\mathrm{S} 1$, which is in agreement with results obtained by XRD and justifies the values of hardness.

Figure 4: Comparison of Seebeck coefficient of TEP measurements with the internal friction damping of MS measurements and the hardness of the sintered samples S0, S05 and S1.

Figure 5 shows the comparison of the spectra of the third heating cycle, carried out up to $1350 \mathrm{~K}$ $\left(1077^{\circ} \mathrm{C}\right)$ for the three samples S0, S05 and S1. Spectra of samples S05 and S1 show one narrow and defined peak at $839^{\circ} \mathrm{C}$ and $826{ }^{\circ} \mathrm{C}$, respectively, while sample S0 shows a wider and more rounded peak at higher temperature $\left(885^{\circ} \mathrm{C}\right)$. As it has been noted above, this peak may correspond with the phase transformation and/or the magnetic transformation of the steel matrix of the cermet. Notice that in correspondence with the IF peaks a dip in the elastic shear modulus is observed.

Figure 5: Comparison of third heating (up to $1350 \mathrm{~K}\left(1077^{\circ} \mathrm{C}\right)$ ) spectra of sintered samples S0, S05 and S1

\section{Thermal Analyses (DTA and TM) and Thermocalc calculations}

Figure 6 shows the DTA curves of the samples with different $\mathrm{C}$ content up to temperatures of $1500{ }^{\circ} \mathrm{C}$. The curve corresponding to sample $\mathrm{SO}$ (no $\mathrm{C}$ addition) shows two endothermic peaks: the first one, very tiny, at around $760^{\circ} \mathrm{C}$, and a second one at $1445^{\circ} \mathrm{C}$ corresponding with the appearance of liquid phase in the sample; no other significant events are found. By increasing the $C$ content in samples S05 and S1, some interesting differences can be observed with respect to the S0 sample: the temperature at which liquid phase appears is decreased to $1389{ }^{\circ} \mathrm{C}$ and $1387^{\circ} \mathrm{C}$ respectively (Note that S05 curve shows two peaks in the liquid phase formation). A new peak appears at $838^{\circ} \mathrm{C}$ and $814^{\circ} \mathrm{C}$, respectively, and the small dip already shown in S0 sample also exists, but at a slightly higher temperature, $769^{\circ} \mathrm{C}$.

Figure 6: DTA curves of S0, S05 and S1 sintered samples (Heating rate: $10^{\circ} \mathrm{C} / \mathrm{min}$ )

Thermomagnetometry (TM) curves can help to identify the origin of the low temperature curves of DTA analyses. As it can be seen in Figure 7, TM curves show a sudden drop in the samples weight at slightly different temperatures depending on the $\mathrm{C}$ content: $789{ }^{\circ} \mathrm{C}$ for S0 (sample without $\mathrm{C}$ added); $796{ }^{\circ} \mathrm{C}$ for $\mathrm{S} 05$, and $803^{\circ} \mathrm{C}$ for $\mathrm{S} 1$. The sudden drop in the sample weight corresponds with the Curie temperature of the samples. By comparing the Curie temperature obtained by TM with the DTA curves one can deduce that the first peak in DTA curves corresponds with the change of ferromagnetic to paramagnetic state. The difference in measured temperatures (around $30{ }^{\circ} \mathrm{C}$ ) could be due to the difference between the sample and the thermocouple temperature in thermomagnetometry. It is worth noticing that for samples S05 and S1 the magnetic transformation temperatures are very close while in sample S0 it is $10^{\circ}$ lower. The same trend is observed in the DTA measurements for the first small dip.

Figure 7: TM (thermomagnetometry) curves of S0, S05 and S1 sintered samples. (Heating rate: $10{ }^{\circ} \mathrm{C} / \mathrm{min}$ )

For a better understanding of the other events shown in the DTA curves, the equilibrium phase diagram of the cermets was obtained by Thermocalc software (Figure 8). For the calculation of this equilibrium phase diagram, taking into account the presence of TiCN in the steel matrix, the elements $\mathrm{Ti}, \mathrm{C}$ and $\mathrm{N}$ were introduced in the mass percentages that correspond to a mixture containing 50 vol. $\% \mathrm{M} 2$ and 50 vol. \% TiCN. The amount of $\mathrm{C}$ was varied considering the additional $\mathrm{C}$ added to the mixture $(0.25$ wt. $\%, 0.5$ wt. \% and 1.0 wt. \% with respect to the matrix content). Taking into account all the $\mathrm{C}$ present, including that from a) $\mathrm{TiCN}, \mathrm{b}$ ) the $\mathrm{M} 2$ matrix and $\mathrm{c}$ ) the additional $\mathrm{C}$ added, the total mass percentage of $\mathrm{C}$ varied between $4.37 \mathrm{wt}$. \% for the sample with no additional $\mathrm{C}$, to 5.04 wt. \% for the sample containing $1.0 \mathrm{wt} . \% \mathrm{C}$. The total percentage variation of $\mathrm{C}$ is not large since most of the $\mathrm{C}$ 
is due to the presence of TiCN. The dotted vertical lines shown in Figure 8 represent the compositions with added free carbon.

From the equilibrium phase diagram, it can be stated that the solidus temperature decreases by increasing the carbon content, which is in agreement with the experimental results from DTA measurements; the $\alpha \rightarrow \gamma$ phase transformation temperature also decreases with increasing the carbon content. The region of phase transformation is very narrow for compositions with high $\mathrm{C}$ percentage, which means that for these $\mathrm{C}$ content, the ferrite transformation takes few degrees, while for compositions with lower $\mathrm{C}$ content such transformation takes about $50^{\circ} \mathrm{C}$. This could be the reason why the DTA cannot detect the $\alpha \rightarrow \gamma$ transformation in the S0 sample.

Figure 8: Theoretical phase diagram calculated by Thermocalc. (Dotted vertical lines indicate the composition of the sintered samples S0, S05 and S1).

\section{Discussion}

There would be two possibilities to explain the sharp peaks that appear in the internal friction spectra of the present samples and in particular those containing carbon: the magnetic and the $\alpha \rightarrow y$ transformation. However, the comparison of the internal friction spectra with TM and DTA measurements clearly shows that the maxima that characterize the spectra at between $825{ }^{\circ} \mathrm{C}$ and $885^{\circ} \mathrm{C}$ are related with the $\alpha \rightarrow \gamma$ transformation. The magnetic transition therefore seems not to have much influence on the internal friction spectrum. This may appear in contradiction with the measurements made by Bolognini et al. [22]. These authors find a drop of internal friction at the Curie temperature and another one at the temperature of the $\alpha \rightarrow \gamma$ transformation. However, these measurements were made in the $\mathrm{MHz}$ frequency range. At these frequencies the contribution of micro-Eddy currents to internal friction is high [23].

Apparently, in the present case $(1 \mathrm{~Hz})$ the magnetic component does not have a strong influence on internal friction. Considering the $\alpha \rightarrow \gamma$ transition only, it is noticeable that a strong increase of damping is observed before the transition. This might be due to an increase of dislocation mobility or to a drop of the elastic constants before the transition. We are therefore in presence of a pre-transitional phenomenon. In the present case, a drop in the elastic shear modulus is visible before the transition in Figure 5. A drop of the elastic constants (soft mode) in martensitic transformations has been discussed by Bideaux [24], who gets to the conclusion that in cobalt no soft mode exists and that the pre-transitional drop of elastic constants is due to the increased mobility of dislocation. In iron, the transformation is not really martensitic and proceeds by nucleation an growth. Since in the present case we have a composite material, it is likely that dislocations play a major role for accommodation. Clearly, the comparison of the three grades shows that the $\alpha \rightarrow \gamma$ transformation occurs at lower temperature when some carbon is added. Moreover, the drop of internal friction at the transformation is sharper. It is unlikely that this could be due to the presence of martensite. In fact, at that temperature all martensite is transformed into ferrite [17]. However, the presence of martensite might be inferred by the increase of TEP in samples S1 and S05. Internal friction is quite a sensitive method to detect the presence of martensite. In fact, as demonstrated in [16, 25] the presence of a huge Snoek-Köster type peak is detected at around $500 \mathrm{~K}$ in martensitic carbon steels. Effectively a peak is detected in S05 that show the maximum hardness and minimum TEP. In [17], it is clearly shown that TEP provides quite a good assessment of the quantity of martensite present in carbon steels. The presence of retained austenite and the high value of hardness in samples with C addition (S05 and S1) could also indicate the presence of martensite in the metallic matrix of these samples.

The equilibrium phase diagram shows that the solidus temperature decreases by increasing the $\mathrm{C}$ content; this result is in agreement with the decrease of the melting point (appearance of liquid phase) 
found in DTA curves of the samples. The same phase diagram also justifies the decrease of the transformation, $\alpha \rightarrow \gamma$ temperature by increasing the $C$ content.

Table 3 summarizes phase and magnetic transformation temperatures of S0, S05 and S1 sintered samples measured by MS, TM and DTA, and compares them with those calculated with the equilibrium phase diagram for the same compositions. The results are satisfactory showing similar transformation temperatures. The combination of these techniques seems therefore a good approach to understand these complex materials.

Table 3: Transformation temperatures measured by DTA, TM and MS of S0, S05 and S1 sintered samples, and calculated in the equilibrium phase diagram of their compositions

\section{Conclusions}

The magnetic and phase transformations of a steel-matrix cermet with 50 vol\% TiCN particles have been identified by means of a combination of techniques, such as Mechanical Spectroscopy (MS), Differential Thermal Analysis (DTA), Thermomagnetometry (TM) and Thermoelectrical Power (TEP). These results are relevant for heat treatment and high temperature behavior of the materials.

MS can also indicate that in the composite material the magnetic component does not have a strong influence on internal friction. The strong increase of damping observed before the $\alpha \rightarrow \gamma$ transition might be due to an increase of dislocation mobility.

The study of the influence of $\mathrm{C}$ content reveals differences between materials: the solidus temperature as well as the $\alpha \rightarrow \gamma$ phase transformation and magnetic transformation of M2/TiCN cermet are decreased by increasing the $\mathrm{C}$ content of the steel matrix. MS technique also reveals a sharper drop of internal friction at the $\alpha \rightarrow \gamma$ phase transformation when the $C$ content increases.

The high hardness of samples with $\mathrm{C}$ addition combined with the presence of retained austenite indicates the presence of martensite in the steel matrix, which is confirmed by the low value of TEP of these samples.

\section{Acknowledgements}

The authors would like to acknowledge the financial support from the Spanish Ministry of Science and Innovation through the R\&D Project MAT2009-14448-C02 and Regional Government of Madrid through the program ESTRUMAT-CM (Ref. S2009/MAT-1585).

\section{References}

[1] Aigner K, Lengauer W, Ettmayer P. Interactions in iron-based cermet systems. J. Alloys Compd. 1997;262-263:486-91.

[2] Umanskii AP. Titanium carbonitride composite with iron chromium binder. Powder Metall. Met. Ceram. 2001;40:637-40.

[3] Li Y, Liu N, Zhang X, Rong C. Effect of WC content on the microstructure and mechanical properties of $(\mathrm{Ti}, \mathrm{W})(\mathrm{C}, \mathrm{N})$-Co cermets. Int. J. Refract. Met. Hard Mater. 2008;26:33-40. 
[4] Rahimi Dizaji V, Rahmani M, Faghihi Sani M, Nemati Z, Akbari J. Microstructure and cutting performance investigation of $\mathrm{Ti}(\mathrm{C}, \mathrm{N})$-based cermets containing various types of secondary carbides. Int. J. Mach. Tools Manuf. 2007;47:768-72.

[5] Kim J, Kang S. Microstructure evolution and mechanical properties of (Ti0.93W0.07)C-xWC-20Ni cermets. Mater. Sci. Eng., A. 2011;528:3090-5.

[6] Yang JK, Lee H-C. Microstructural evolution during the sintering of a Ti(C,N)Mo2CNi alloy. Mater. Sci. Eng., A. 1996;209:213-7.

[7] Liu N, Liu X, Zhang X, Zhu L. Effect of carbon content on the microstructure and mechanical properties of superfine Ti(C, N)-based cermets. Mater. Charact. 2008;59:1440-6.

[8] Li Y, Liu N, Zhang X, Rong C. Effect of carbon content on the microstructure and mechanical properties of ultra-fine grade (Ti,W) (C,N)-Co cermets. J. Mater. Process. Technol. 2008;206:365-73.

[9] Zackrisson J, Andrén HO. Effect of carbon content on the microstructure and mechanical properties of (Ti, W, Ta, Mo)(C, N)-(Co, Ni) cermets. Int. J. Refract. Met. Hard Mater. 1999;17:265-73.

[10] Zheng Y, Liu W, Wang S, Xiong W. Effect of carbon content on the microstructure and mechanical properties of Ti(C, N)-based cermets. Ceram. Int.. 2004;30:2111-5.

[11] Alvaredo P, Gordo E, Van der Biest O, Vanmeensel K. Microstructural development and mechanical properties of iron based cermets processed by pressureless and spark plasma sintering. Mater. Sci. Eng., A. 2012;538:28-34.

[12] Mari D, Bolognini S, Viatte T, Benoit W. Study of the mechanical properties of TiCN-WC-CO hardmetals by the interpretation of internal friction spectra. Int J Refract Met Hard Mat. 2001;19:25765.

[13] Mari D. Understanding the mechanical properties of hardmetals through mechanical spectroscopy. Mater. Sci. Eng., A. 2009;521-22:322-8.

[14] Mari D, Bolognini S, Feusier G, Viatte T, Benoit W. Experimental Strategy to Study the Mechanical Behaviour of Hardmetals for Cutting Tools. Int J Refr Metals Hard Mater. 1999;17:209-25.

[15] Martin R, Mari D, Schaller R. Influence of the carbon content on dislocation relaxation in martensitic steels. Mater Sci Eng A. 2009;521-522:117-20.

[16] Tkalcec I, Azcoltia C, Crevoiserat S, Mari D. Tempering effects on a martensitic high carbon steel. Mater. Sci. Eng., A. 2004;387-389:352-6.

[17] Tkalcec I, Mari D, Benoit W. Correlation between internal friction background and the concentration of carbon in solid solution in a martensitic steel. Mater. Sci. Eng., A. 2006;442:471-5.

[18] Borrelly $R$, Benkirat $D$. Sensibilité du pouvoir thermoélectrique à l'état microstructural du fer et du fer-azote. Acta Metall. 1985;33:855-66.

[19] Tkalcec I. Mechanical Spectrocopy in high carbon steels: Ècole Polytechnique Fèdèrale de Lausanne 2004. 
[20] Andersson JO, Helander T, Höglund L, Shi P, Sundman B. Thermo-Calc \&amp; DICTRA, computational tools for materials science. Calphad. 2002;26:273-312.

[21] Rupard RG, Gallagher PK. The thermal decomposition of coprecipitates and physical mixtures of magnesium-iron oxalates. Thermochim. Acta. 1996;272:11-26.

[22] Bolognini S, Moreau A. Ultrasonic absorption in ultra-low carbon steel. J. Appl. Phys. 2003;94:3771-80.

[23] Degauque J. Magnetic domains. Mater Sci Forum. 2001;366-3:453-82.

[24] Bidaux JE, Schaller R, Benoit W. Study of the h.c.p.-f.c.c. phase transition in cobalt by acoustic measurements. Acta Metall. 1989;37:803-11.

[25] Martin R, Tkalcec I, Mari D, Schaller R. Tempering effects on three martensitic carbon steels studied by mechanical spectroscopy. Philos. Mag.. 2008;88:2907-20. 


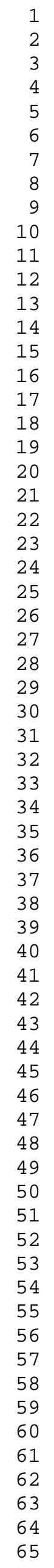


Table 1. Characteristics of raw materials.

\begin{tabular}{|c|c|c|c|c|c|}
\hline \multirow{2}{*}{ Raw material } & \multirow{2}{*}{ Supplier } & \multicolumn{2}{|c|}{ Supplier data } & \multicolumn{2}{c|}{ Experimental data } \\
\cline { 3 - 6 } & & $\begin{array}{c}\text { Density } \\
\left(\mathbf{g} / \mathbf{c m}^{3}\right)\end{array}$ & $\begin{array}{c}\text { Particle size } \\
(\boldsymbol{\mu m})\end{array}$ & $\begin{array}{c}\text { Density } \\
\left(\mathbf{g} / \mathbf{c m}^{\mathbf{3}}\right)\end{array}$ & $\begin{array}{c}\text { Particle size } \\
(\boldsymbol{\mu m})\end{array}$ \\
\hline $\mathrm{TiC}_{0.5} \mathrm{~N}_{0.5}$ & $\begin{array}{c}\text { H.C. } \\
\text { Starck }\end{array}$ & 5.03 & $\mathrm{D} 50=2.0-4.0$ & 5.12 & $\mathrm{D} 50=3.957$ \\
\hline High Speed Steel, M2 & Osprey & 8.56 & $\mathrm{D} 90<16$ & 8.09 & $\mathrm{D} 50=8.147$ \\
\hline
\end{tabular}

Table 2. Hardness and relative density of sintered samples S0, S05 and S1

\begin{tabular}{|c|c|c|}
\hline Sample & Hardness (HV30) & Relative density (\%) \\
\hline S0 & $665 \pm 35$ & 96.4 \\
\hline S05 & $1336 \pm 9$ & 100.6 \\
\hline S1 & $1348 \pm 28$ & 100.4 \\
\hline
\end{tabular}

Table 3: Transformation temperatures measured by DTA, TM and MS of S0, S05 and S1 sintered samples, and calculated in the equilibrium phase diagram of their compositions

\begin{tabular}{|c|c|c|c|c|c|}
\hline \multirow{2}{*}{ Sample } & \multicolumn{2}{|c|}{$\alpha \rightarrow$ p phase transformation temperature $\left({ }^{\circ} \mathbf{C}\right)$} & \multicolumn{2}{|c|}{$\begin{array}{c}\text { Magnetic transformation. } \\
\text { Curie temperature }\left({ }^{\circ} \mathbf{C}\right)\end{array}$} \\
\cline { 2 - 6 } & DTA & Mechanical Spectroscopy & ThermoCalC & DTA & Thermomagnetometry \\
\hline S0 & - & 885 & 870 & 760 & 789 \\
\hline S05 & 838 & 839 & 815 & 769 & 796 \\
\hline S1 & 814 & 826 & 800 & 769 & 803 \\
\hline
\end{tabular}



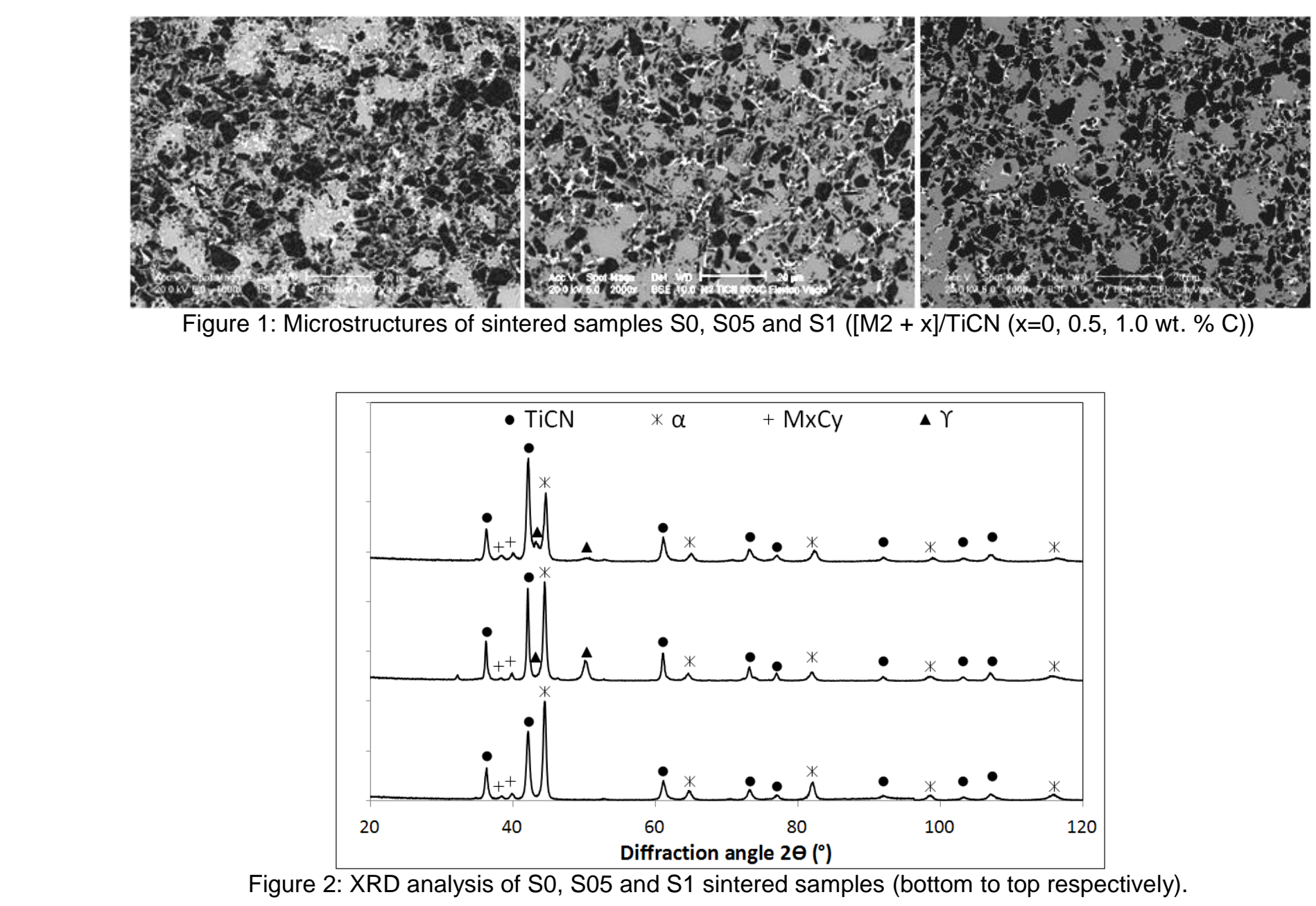

Figure 1: Microstructures of sintered samples S0, S05 and S1 ([M2 + x]/TiCN (x=0, 0.5, 1.0 wt. \% C))

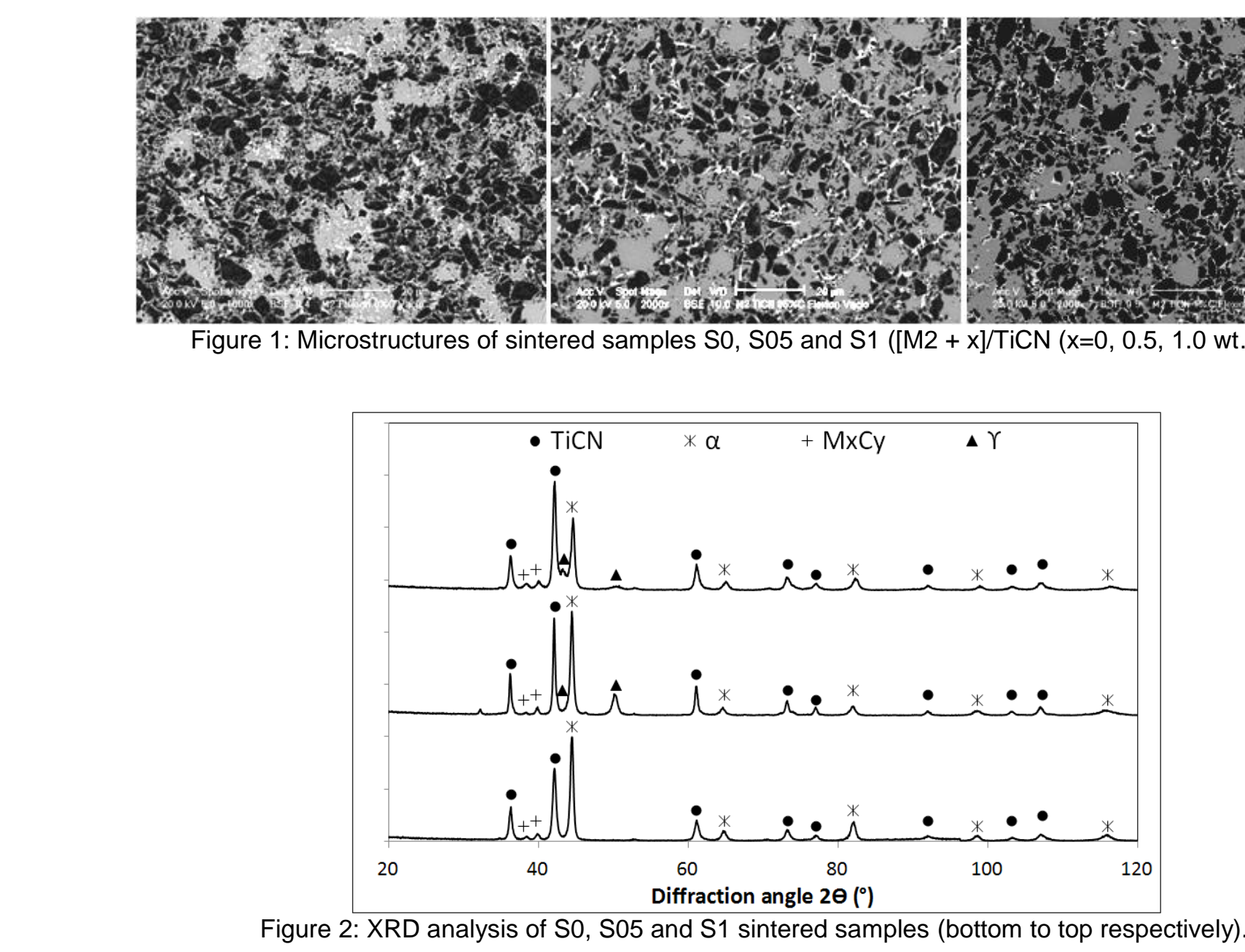

Figure 2: XRD analysis of S0, S05 and S1 sintered samples (bottom to top respectively).

\footnotetext{
Figure:XRD analysis of S0, S05 and S1 sintered samples (bottom to top respectively).
}

(1)

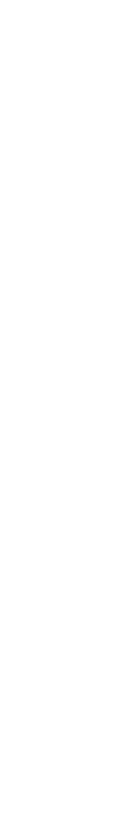




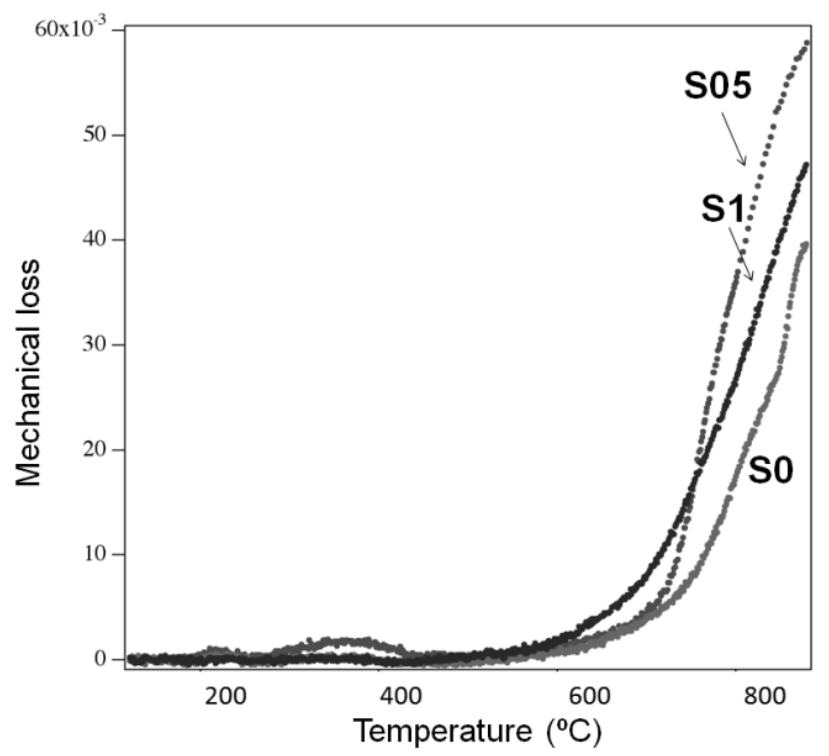

Figure 3: Comparison of first heating (up to $1100 \mathrm{~K}\left(827^{\circ} \mathrm{C}\right)$ ) spectra of sintered samples S0, S05 and S1.

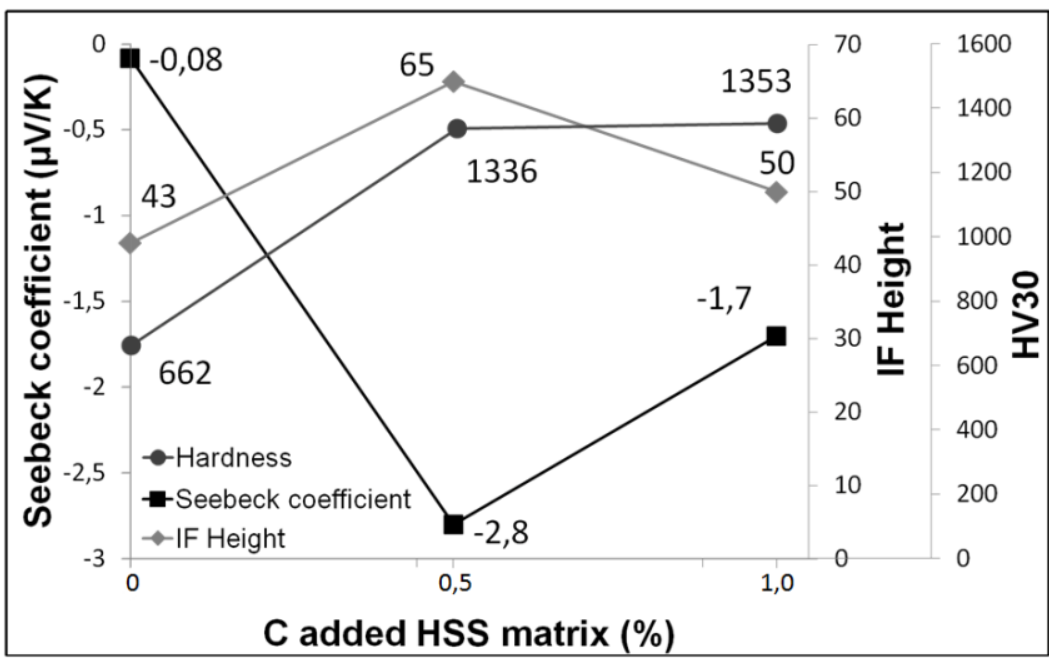

Figure 4: Comparison of Seebeck coefficient of TEP measurements with the internal friction damping of MS measurements and the hardness of the sintered samples S0, S05 and S1. 


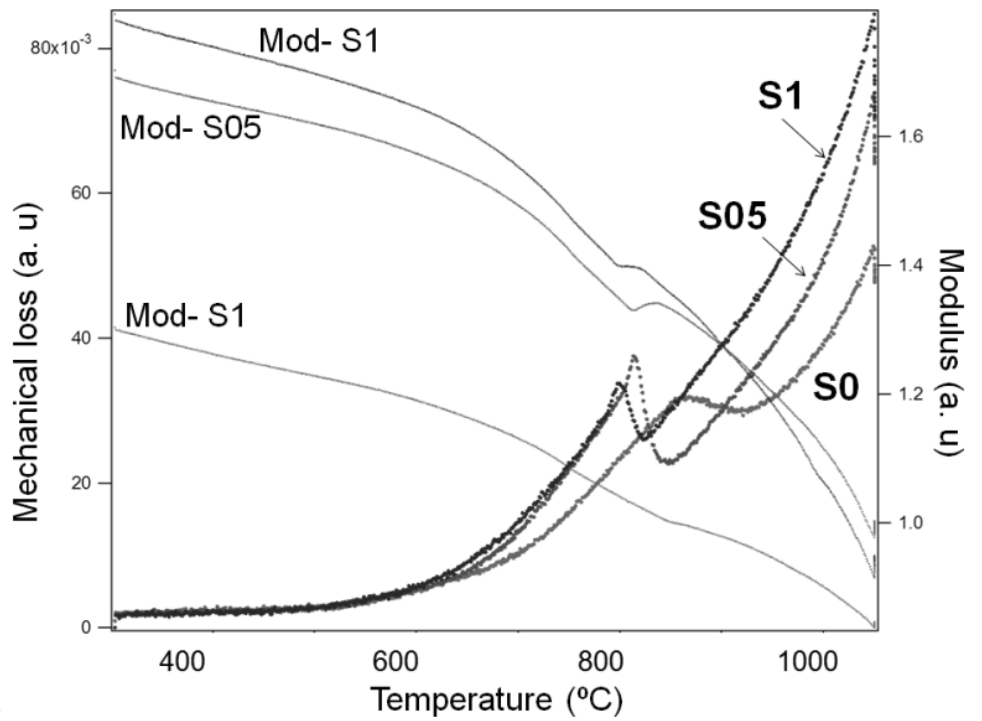

Figure 5: Comparison of third heating (up to $1350 \mathrm{~K}\left(1077^{\circ} \mathrm{C}\right)$ ) spectra of sintered samples S0, S05 and S1

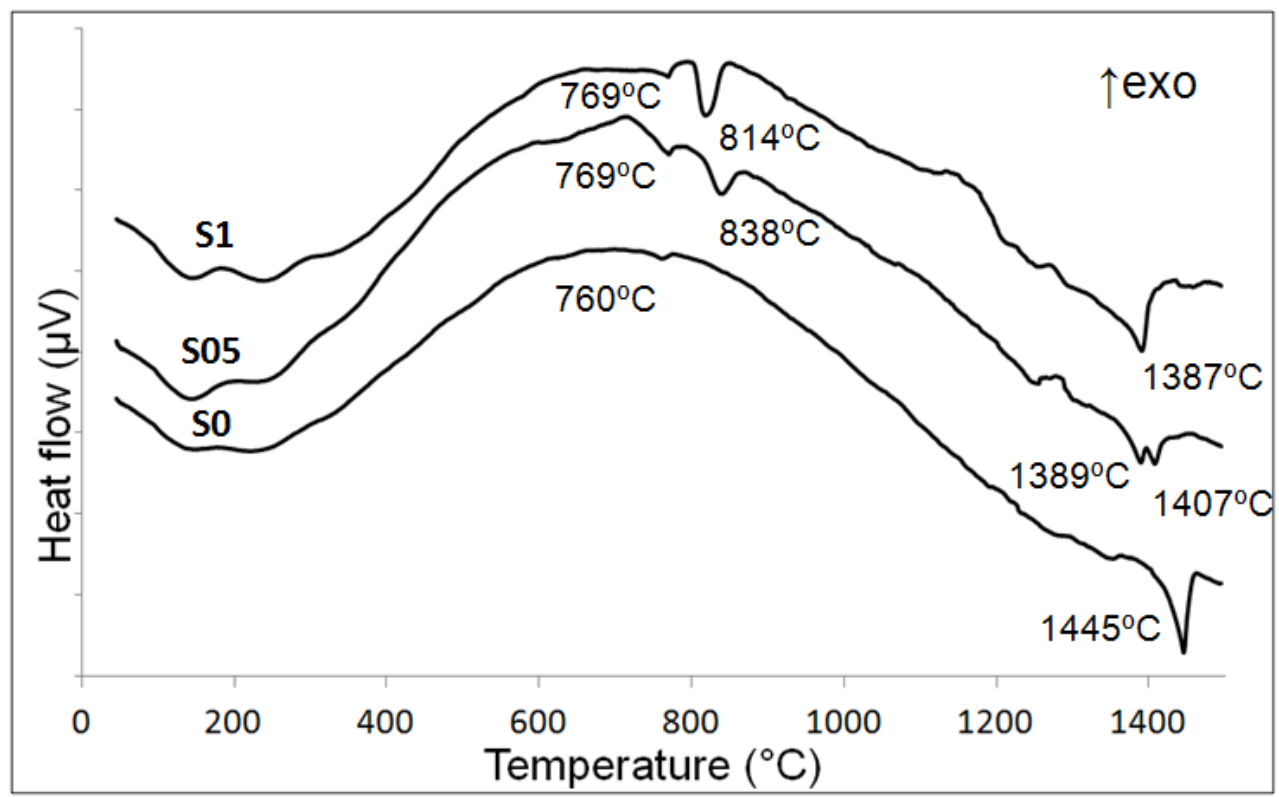

Figure 6: DTA curves of S0, S05 and S1 sintered samples (Heating rate: $10^{\circ} \mathrm{C} / \mathrm{min}$ ) 


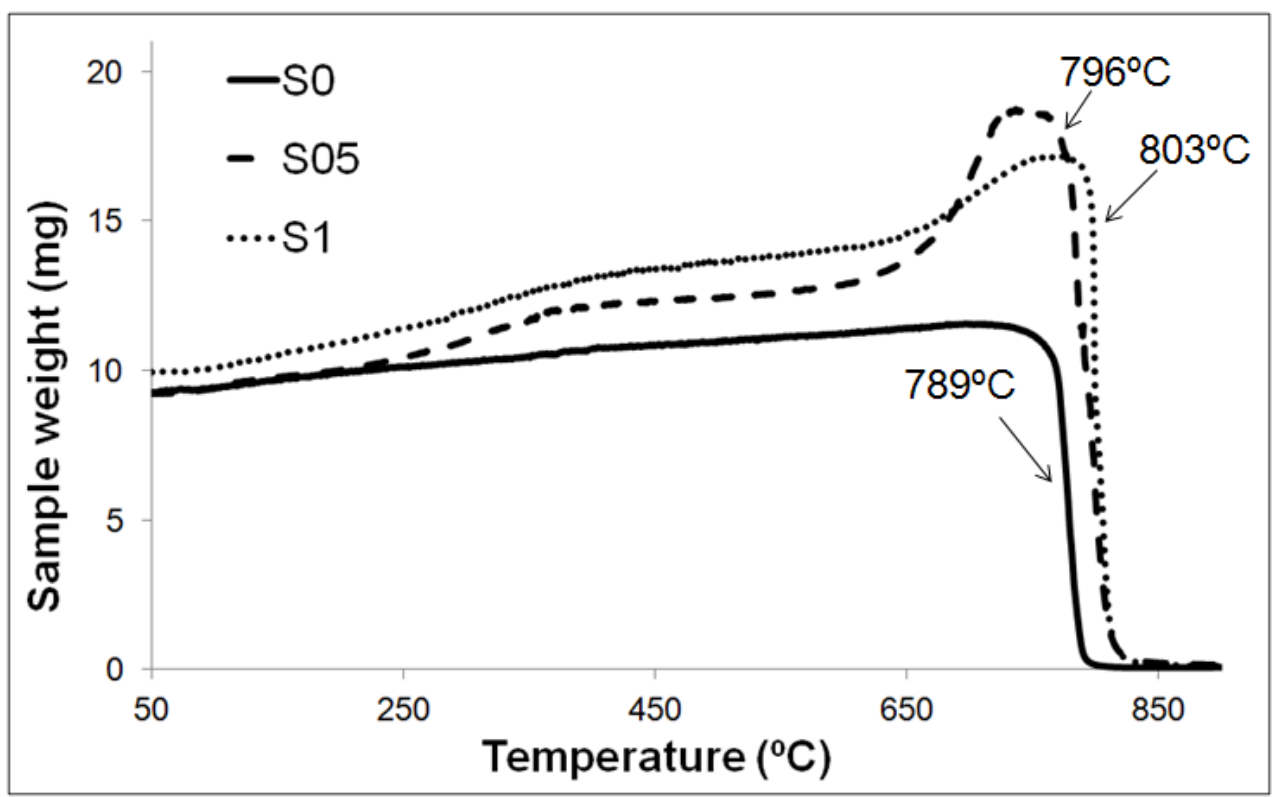

Figure 7: TM (thermomagnetometry) curves of S0, S05 and S1 sintered samples. (Heating rate: $10 \stackrel{\circ}{\circ} / \mathrm{min}$ )

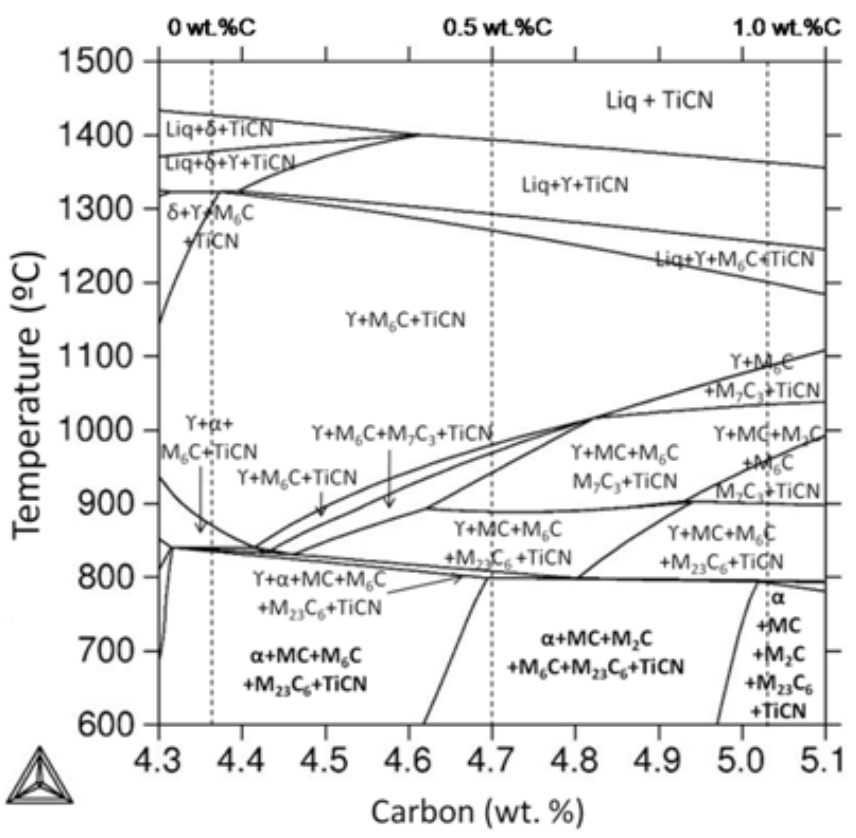

Figure 8: Theoretical phase diagram calculated by Thermocalc. (Dotted vertical lines indicate the composition of the sintered samples S0, S05 and S1). 